\title{
Optimum position of isolators within erbium-doped fibers
}

Lumholt, Ole; Schüsler, Kim; Bjarklev, Anders Overgaard; Dahl-petersen, Svend; Povlsen, Jørn Hedegaard; Rasmussen, Thomas; Rottwitt, Karsten

Published in:

I E E E Photonics Technology Letters

Link to article, DOI:

$10.1109 / 68.141970$

Publication date:

1992

Document Version

Publisher's PDF, also known as Version of record

Link back to DTU Orbit

Citation (APA):

Lumholt, O., Schüsler, K., Bjarklev, A. O., Dahl-petersen, S., Povlsen, J. H., Rasmussen, T., \& Rottwitt, K. (1992). Optimum position of isolators within erbium-doped fibers. I EE E Photonics Technology Letters, 4(6), 568-570. https://doi.org/10.1109/68.141970

\section{General rights}

Copyright and moral rights for the publications made accessible in the public portal are retained by the authors and/or other copyright owners and it is a condition of accessing publications that users recognise and abide by the legal requirements associated with these rights.

- Users may download and print one copy of any publication from the public portal for the purpose of private study or research.

- You may not further distribute the material or use it for any profit-making activity or commercial gain

- You may freely distribute the URL identifying the publication in the public portal

If you believe that this document breaches copyright please contact us providing details, and we will remove access to the work immediately and investigate your claim 


\section{Optimum Position of Isolators within Erbium-Doped Fibers}

Ole Lumholt, Kim Schüsler, Anders Bjarklev, Svend Dahl-Petersen, J $\phi \mathbf{r n}$ H. Povlsen, Thomas Rasmussen, and Karsten Rottwitt

\begin{abstract}
An isolator is used as an amplified spontaneous emission suppressing component within an erbium-doped fiber. The optimum isolator placement is both experimentally and theoretically determined and found slightly dependent upon pump power. Improvements of $4 \mathrm{~dB}$ in gain and $2 \mathrm{~dB}$ in noise figure are measured for the optimum isolator location at $25 \%$ of the fiber length when the fiber is pumped with $60 \mathrm{~mW}$ of pump power at $1.48 \mu \mathrm{m}$.
\end{abstract}

\section{INTRODUCTION}

$\mathrm{T}$ HE development within the field of optimizing the gain efficiencies of erbium-doped fibers [1] has revealed in a tremendous increase to more than $10 \mathrm{~dB} / \mathrm{mW}$ for fibers with gain optimized designs [2]. Even for these fibers most of the pump photons are still lost to amplified spontaneous emission (ASE) yielding gain saturation as the ASE becomes comparable with the pump power at the fiber ends. The ASE at the signal input end is especially unwanted, as a low noise figure is depended upon a high population inversion in this part of the fiber. Obviously, a way to reduce the accumulation of backward traveling ASE is to insert an isolator within the active fiber [3]. Numerical calculations have shown [3] that for favorable locations of the isolator, a remarkably improved gain and a noise figure close to the theoretical lower limit can be obtained. Recently, a work was presented [4] with an isolator inserted among two pieces of erbium-doped fiber, pumped with 0.98 and $1.48 \mu \mathrm{m}$ light, respectively. However, the purpose with that configuration was totally different, as the isolator was employed as a necessity to prevent gain saturation by the $0.98 \mu \mathrm{m}$ light amplifying the $1.48 \mu \mathrm{m}$ pump light.

\section{THEORY}

Consider the situations where the length of an erbium-doped fiber is gain optimized. If an isolator is inserted at the input end of this fiber, a gain reduction and a noise deterioration arises because both signal and pump are attenuated by the isolator insertion loss. Also a location at the signal output end will reduce the gain, as in this case, the output signal power

Manuscript received December 23, 1991. This work was supported by the Danish Technical Research Council and the National Agency of Industry and Trade, Denmark.

O. Lumholt, A. Bjarklev, J. H. Povlsen, T. Rasmussen, and K. Rottwitt are with the Center for Broadband Telecommunications, Electromagnetics Institute, Technical University of Denmark, DK-2800 Lyngby, Denmark.

K. Schüsler and S. Dahl-Petersen are with NKT Research Center, DK-2605 Brondby, Denmark.

IEEE Log Number 9200303. is attenuated by the insertion loss. If counter propagating pump is present for this placement of the isolator, a further deterioration of both gain and noise figure occur, as the pump power is affected by both the isolation and the insertion loss. Looking next at the situation with the isolator placed within the active fiber, in a distance $L 1$ from the signal input end, less pump power is lost in the isolator and the signal gain in the first part of the erbium-doped fiber increases because backward ASE is reduced by the isolator. This exemplifies the existence of an optimum placement of the isolator within the active fiber.

\section{EXPERIMENTAL SETUP}

The experimental setup for evaluating the gain characteristics is shown in Fig. 1. The pump and signal laser diodes are emitting at $1.48 \mu \mathrm{m}$ and $1.55 \mu \mathrm{m}$ respectively. An ordinary bidirectional pumping scheme is adapted and regulated so exactly the same amount of pump power is launched into the erbium fiber ends. To determine the launched pump power, a 1:99 coupler is inserted between the pump and the WDMcoupler at each fiber end. All free fiber ends in these, as well as in the other couplers, are cleaved in angles of $10^{\circ}$ to prevent unwanted reflections. The erbium doped $\mathrm{Al}_{2} \mathrm{O}_{3}-\mathrm{SiO}_{2}$ fiber has a numerical aperture of 0.31 , a cutoff wavelength of $0.98 \mu \mathrm{m}$ and has further been described in [5]. The isolator, which is inserted within the erbium fiber has an insertion loss of $1.5 \mathrm{~dB}$, including the splice losses to the erbium fiber, and an isolation of $40 \mathrm{~dB}$. The ASE spectrum around the signal and the total ASE spectrum, recorded by a double monochromator, are calibrated by a power measurement of the total ASE, and used to evaluate the noise figure.

\section{Results and Discussion}

The length of the erbium-doped fiber has been gain optimized when inserted in the above mentioned pumping configuration, but without any isolator located between the fiber ends, and receiving a total of $60 \mathrm{~mW}$ launched pump power. The measured maximum gain of $37.9 \mathrm{~dB}$ and the corresponding noise figure of $7.4 \mathrm{~dB}$ are used and denoted as reference measurements in the remaining of this communication.

Corresponding measurements of gain and noise figure for a variety of total pump power levels are shown in Fig. 2 versus the relative location of the isolator within the reference fiber. That is the ratio between the erbium fiber length among the signal input end and the isolator, and the total length of the erbium-doped fiber. The predicted existence of an optimum location of an isolator within the fiber is clearly verified in 


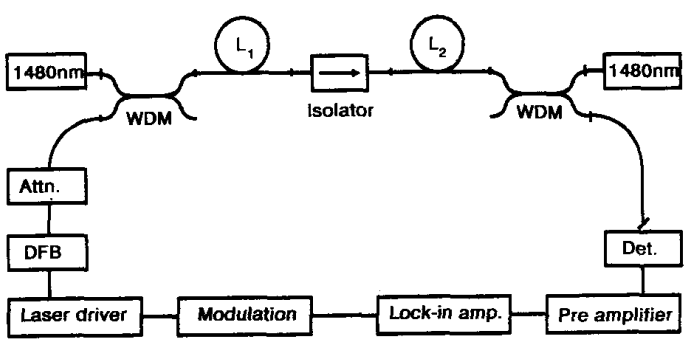

Fig. 1. Experimental setup. Not shown in the figure are monitor couplers at the signal input end of the two pump inputs.

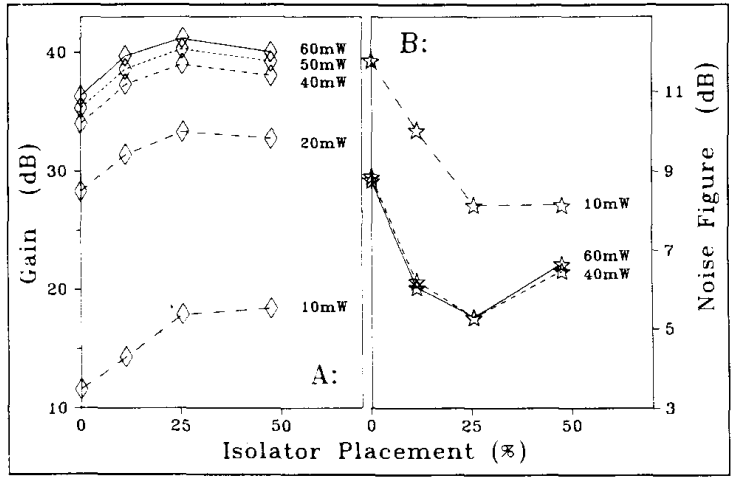

Fig. 2. Measured gain and noise figure versus the relative isolator placement between 0 and $50 \%$ of the total fiber length. Shown for pump power levels between 10 and $60 \mathrm{~mW}$.

the figure, showing a pump power dependent optimum placement between 25 and $40 \%$. The optimum relative location is slightly decreasing for increasing pump power. It is seen that the noise figure also improves with increasing pump power until a noise floor is reached for a pump power higher than $40 \mathrm{~mW}$. The noise figure is constrained by the presence of stimulated emission at the pump wavelength giving a fundamental lower noise figure limit that very closely is reached in this situation. Using $60 \mathrm{~mW}$ of pump power, a maximum gain of $41.2 \mathrm{~dB}$, and a noise figure of $5.3 \mathrm{~dB}$ are measured. This is an improvement of $3.3 \mathrm{~dB}$ in gain and $2.1 \mathrm{~dB}$ in noise figure compared to the reference and it is respectively $5 \mathrm{~dB}$ and $3.5 \mathrm{~dB}$ better than the situation with the isolator placed at the signal input end of the amplifier.

Along with the reduced ASE, the gain optimized fiber length will increase. For a total use of $60 \mathrm{~mW}$ pump power, the overall highest gain of $42.0 \mathrm{~dB}$ and a corresponding noise figure of $5.4 \mathrm{~dB}$ are measured when both the isolator location and the fiber length are optimized. Compared to the reference, the improvements are $4.1 \mathrm{~dB}$ in gain and $2 \mathrm{~dB}$ in noise figure and the increase in optimized fiber length is $25 \%$. In comparison with measurements for two other isolator placements (10 and $40 \%)$ of this fiber length, the improvements are shown as stars in Fig. 3(a) and (b).

Numerical calculations are made by use of an accurate model [6] which has been extended in [3]. Numerous measured data for the considered fiber, in a pumping scheme similar to the experiment, are used as input parameters to the

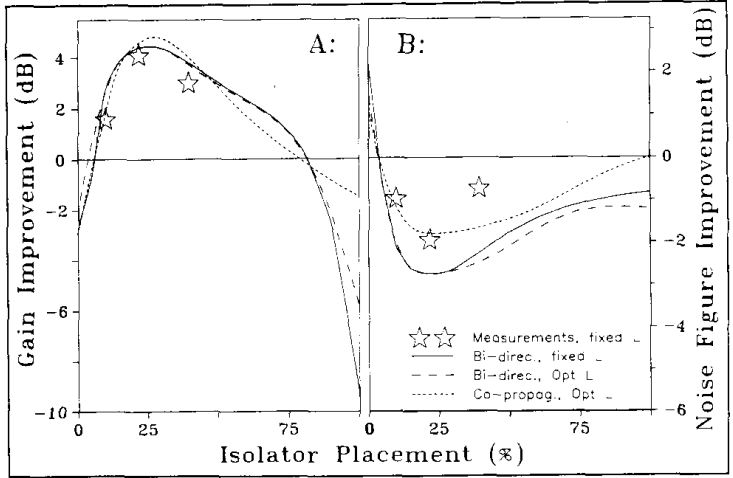

Fig. 3. (a) Gain versus relative isolator placement among 0 and $100 \%$ of the total fiber length. (b) Noise figure versus relative isolator placement Measurements illustrated by stars. Calculations corresponding to the experiment are shown as solid lines. Calculations at gain optimized lengths in a bidirectional and copropagating pumping scheme are shown as dashed and dotted lines, respectively.

model. Calculations are shown in Fig. 3 for various relative placements of the isolator. The solid lines correspond to the measured data. The fiber length is gain optimized with the isolator at the optimum position, and this total fiber length is kept unchanged for other relative locations of the isolator. The dashed lines illustrate the situation when the total fiber length is gain optimized for each relative location of the isolator. To generalize the analysis, corresponding calculations are made for a copropagating pumping scheme (dotted lines).

Looking first at the gain, the difference between measured and calculated improvements are less than $1 \mathrm{~dB}$, and the optimum isolator placement in the bidirectional pumping scheme is both calculated and measured to be $25 \%$ of the fiber length. For the copropagating scheme, the optimum placement is a few percent larger. Although the improvement is largest for this configuration, the overall highest gain is obtained by the bidirectional scheme, as the reference gains are 34.9 and $36.1 \mathrm{~dB}$, respectively. A net gain is obtained for both configurations, as long as the isolator is placed within $10-80 \%$ of the fiber length. The large gain penalty observed for an isolator at the output end of the bidirectional pumping scheme, is caused by the attenuation of the backward pump power by $40 \mathrm{~dB}$ isolation and the splice losses to the isolator. In the copropagating scheme, only the output signal power is reduced by the $1.5 \mathrm{~dB}$ insertion loss when located at this position.

Looking next at the noise figure, it is seen that the measured improvement is up to $1.5 \mathrm{~dB}$ less than predicted (solid line), but still the course in both cases is very similar. It is seen that the optimum isolator location with respect to noise figure is a few percentages lower than the gain optimized. Although the improvement for the bidirectional case is $1 \mathrm{~dB}$ better than for the copumped, both configurations result in the same low noise figure. This is due to the noise figures for the reference fiber, which in the bidirectional configuration is $1 \mathrm{~dB}$ higher than for copumped scheme $(7.2$ and $6.2 \mathrm{~dB}$, respectively). 


\section{CONCLUSION}

The use of an isolator has experimentally been verified to be a simultaneous gain and noise figure improvement component, when inserted within the erbium-doped fiber. The optimum location of the isolator is determined in the range of $25-40 \%$ of the fiber length, decreasing for increased pump power, for both copumped and bidirectional pumped amplifiers. For this location, the noise figure comes close to the theoretical lower limit. For $60 \mathrm{~mW}$ pump power at $1.48 \mu \mathrm{m}$, an increase of $25 \%$ in the gain-optimized fiber length was determined when the isolator was inserted at the optimum location of $25 \%$ of the fiber length. Compared with a gain optimized fiber without any isolator, improvements of more than $4 \mathrm{~dB}$ in gain and $2 \mathrm{~dB}$ in noise figure were measured, yielding $42 \mathrm{~dB}$ gain and a $5.4 \mathrm{~dB}$ noise figure.

\section{ACKNOWLEDGMENT}

The authors thank Dr. E. Nicolaisen for fruitful discussions.

\section{REFERENCES}

[1] B. Pedersen, A. Bjarklev, O. Lumholt, and J. H. Povlsen, "Detailed design analysis of erbium doped fiber amplifiers," IEEE Photon. Technol. Lett., vol. 3, pp. 548-550, June 1991.

[2] M. Nakazawa, Y. Kimura, and K. Suzuki, "An ultra-efficient erbium-doped fiber amplifier of $10.2 \mathrm{~dB} / \mathrm{mW}$ at $0.98 \mathrm{~nm}$ pumping and $5.1 \mathrm{~dB} / \mathrm{mW}$ at $1.48 \mu \mathrm{m}$ pumping," in Proc. Opt. Amplifier Appl., Monterey, CA, 1990, pp. PdP1-1-3.

[3] J. H. Povlsen, A. Bjarklev, O. Lumholt, H. Vendeltorp-Pommer, and K. Rottwitt, "Optimizing gain and noise performance of EDFA's with insertion of a filter or an isolator," in Proc. SPIE OE/FIBERS '91, 1991.

[4] Y. Aoki, T. Saito, K. Fukagai, Y. Sunohara, S. Ishikawa, and S. Fujita, "Low noise and high saturation output power erbium-doped fiber amplifiers pumped with $0.98 \mu \mathrm{m}$ and $1.48 \mu \mathrm{m}$ LDs for long-distance optical communication," in Proc. 17th ECOC '91, Paris, 1991 , pp. $585-588$

[5] O. Lumholt, K. Dybdal, C. C. Larsen, S. Dahl-Petersen, K. Schüsler, A. Bjarklev, J. H. Povlsen, T. P. Rasmussen, and K. Rottwitt, "Er-La doped fibre amplifier, pumped at $1.47 \mu \mathrm{m}$," in Proc. 17th ECOC '91, Paris, 1991, pp. 285-288.

[6] B. Pedersen, A. Bjarklev, J. H. Povlsen, K. Dybdal, and C. C. Larsen, "The design of erbium-doped fiber amplifiers," J. Lightwave Technol., vol. 9, no. 9, pp. 1105-1112, 1991.

\title{
Amplified Distributed Reflective Optical Star Couplers
}

\author{
Y. K. Chen
}

\begin{abstract}
We present a practical configuration of an amplified distributed reflective $N$-star coupler using $2 \times 2$ 3-dB fiber couplers and minimum numbers of erbium-doped fibers, pump lasers, and standard fibers. The constitution and characteristics of this coupler are investigated. Besides a tremendous saving of the required standard fibers, this distributed coupler is more efficient, more reliable, more flexible for future expansion, and more cost-effective for application in optical networks.
\end{abstract}

\section{INTRODUCTION}

$\mathrm{O}$ PTICAL star networks have the potential to provide very large throughput, and they are expected to find widespread application in upgrading existing networks and photonic networks [1], [2]. In many practical networks, users are geographically distributed in clusters such as several buildings on a campus. Hence, using a distributed star coupler is better than a centralized one [3]. The numbers of fibers and components required to implement a star network

Manuscript received December 6, 1991; revised march 23, 1992.

The author is with the Applied Research Laboratory, Telecommunication Laboratories, Ministry of Transportation and Communications, Chung-Li 32099, Taiwan, R.O.C

IEEE Log Number 9200729. can be reduced to a half by using a reflective $N$-star coupler instead of a transmissive $N \times N$ star coupler [4]. However, the inherent $1 / N$ splitting and excess losses may limit the ultimate size and throughput of the star network [5]. Some researches with incorporation of erbium-doped fiber amplifiers (EDFA's) for accommodating more users, $N$, had been shown in centralized star couplers [6]-[8]. So the distributed reflective star coupler incorporating EDFA's is expected to have better performance and applications in practical networks.

In this letter, we present a configuration for constructing the amplified distributed reflective $N$-star fiber coupler using $2 \times 23$-dB fiber couplers and minimum numbers of erbiumdoped fibers (EDF's), pump lasers, and standard fibers. The constitution, characteristics, and features of this coupler are investigated.

\section{Configuration}

The amplified distributed reflective $N$-star coupler with $N=m^{2}$ and $N=2 \mathrm{~m}^{2}$ is similar to the centralized reflective active star coupler, but it is divided into small parts and these parts are distributed over $n$ nodes (i.e., locations) uniformly around a circle of diameter $D$ of the network 